\title{
Perception of Final Year Nigeria Nursing Students on Objective Structured Clinical Examination: A viewpoint of Oyo State College of Nursing and Midwifery, Eleyele, Ibadan, Nigeria
}

\author{
Funmilayo Abiola Opadoja ${ }^{*}$, Samuel Olukayode Awotona ${ }^{2}$, Oluwaseun Lekan Ipadeola ${ }^{2}$ \\ ${ }^{1}$ Lecturer, Oyo state College of Nursing and Midwifery, Eleyele, Ibadan, Nigeria \\ ${ }^{2}$ Librarian, Oyo state College of Nursing and Midwifery, Eleyele, Ibadan, Nigeria
}

*Corresponding Author: Funmilayo Abiola Opadoja, Lecturer, Oyo state College of Nursing and Midwifery, Eleyele, Ibadan, Nigeria. Email: funmiopadoja@yahoo.com

\begin{abstract}
Objective Structured Clinical Examination (OSCE) is a kind of clinical assessment of nursing student's skills. Therefore OSCE is used to sum the assessment of practical knowledge and skills in nursing education. In view of this, the paper dwells on investigation the perceptions of the final year nursing students on the Objective Structured Clinical examination and its acceptance among the students.
\end{abstract}

The purpose of this research is to explore and investigate the perceptions of the final year nursing students, on the use of OSCE as a means of clinical practical assessment.

Keywords: Assessment, Nursing Students, Objective Structured Clinical Examination, Clinical practical Assessment.

\section{INTRODUCTION}

Assessment is a very important component in training and it is regarded as a reliable tool when reviewing the level of students' learning. The knowledge students have gathered and how they can put the knowledge into use are usually evaluated by written tests. Clinical nursing education is the heart of a nurses' professional practice and therefore the evaluation of nursing students"e clinical competencies is critical to their education. In order to develop and actively respond to rapidly changing health environments, the nurses should be trained in the current standards and advances and must possess excellent nursing skills [1].

The convectional way otherwise referred to as Traditional Practical Examination (TPE) is assessing nursing student's practical skill (psychomotor skill) had been on use since onset of nursing training. This comprises the use of two well trained and seasoned examiners forming a panel to measure the student's practical performance. The practical examination which includes instructions and questions are based on the examiners view. Students are allowed to face each examiner for 30 minutes. A panel will eventually spend an hour with each candidate.
The students are allowed to have interaction with real and life patient in hospital settings. At the end of the practical session, the students will have a viva session of 10 minutes for theory questions, defence of project and care study. There is no objectivity in this method because students are not allowed to face some procedures. Luck or favour may come into play. The overall performance of each candidate is based on examiner's view. Although, there is a checklist but this checklist is generalized for all procedure. The traditional practical examination had been adopted by the Nursing and Midwifery Council of Nigeria for a long period until recently when OSCE was introduced as new method of assessment for nursing students in Nigeria, though not new to the midwifery students

Assessment of clinical experience is an integral part of clinical education therefore every student nurses were subjected to the OSCE which is a summative assessment of practical knowledge and skills in nursing education. The OSCE is becoming more prevalent within healthcare education programmes, because it is regarded as a useful method for assessing, skills, and underpinning knowledge required for practice [2][3] corroborates that OSCE is a form of 
assessment in which student demonstrates clinical skills and underpinning knowledge, usually in simulated conditions.

OSCEs are conducted by means of rotating students in successive stations that assess students' skills in history taking, physical examination, communication skills, patient management, diagnosis and data interpretation. The stations are organised in such a way that it allows students to rotate smoothly in predetermined time while being observed by an examiner or a one to one basis using standard patients.

OSCE as an assessment tool for student nurses' clinical competence is a new method of assessing which brought into use because the nursing profession is characterised by the fact that significant amount of time is spent on competency related activities. These competencies related activities are fundamental to the caring role of nurses and are central to the nursing curriculum. The assessment of clinical competence assessment is therefore an important issue in nursing education and utilization of OSCE for that purpose is considered very important [4].

\section{OBJECTIVE OF THE STUDY}

i. Whether OSCE are used to assess Clinical Skills

ii. Whether students are aware of the OSCE procedure

iii. Whether students finds OSCE stressful or not

iv. Whether time for preparation sufficient

v. Whether the Environment for the OSCE is important for assessment

\section{CONTEXT}

Nursing education comprises both theoretical and practical training procedures. Clinical training is considered as a vital and very important part of professional nursing education. Clinical education is accepted as an essential and highly significant component of professional education for nursing. Practical clinical skills lie at the heart of nurses' professional practice; therefore, the mastery of fundamental clinical skills is an important component of courses leading to registration. Since nursing is a discipline based on practice, there needs to be a curriculum of education that offers students the opportunity to develop their clinical skills, chiefly the patient care skills. Clinical practice is one of the means used to upsurge the nursing students' professional competence. Therefore, it is in the clinical area that students must transmit theory to practice, learn the needed technical and interpersonal skills, make clinical decisions, become mixed into the profession, and begin to appreciate its values and ethics. The development of competent practice is a primary goal for nursing education. To demonstrate this competence, graduates must be able to practice in the "real word [5].

A central component of nursing education is the clinical experience. Students participate in controlled learning sessions in real world health care situations, which provide them with the chance to put what they've learned in the classroom into practice [8], which provide them with the chance to put what they've learned in the classroom into practice. [6] stated that Clinical Nursing is a term which describes the functions and responsibilities of a nurse engaged in providing direct services to people as opposed to the nurse whose functions and responsibilities relate to administration, education or research.

Having the knowledge of what Clinical education mean and its importance in the general development of a nursing student, there is a need to assess how the student nurses had fair in their clinical postings before they are licensed or become a registered nurse that can be allow to practice.

[5] opined that clinical competence assessment is defined as a cohesive form of appraisal seeking to combine knowledge, understanding, problem solving, technical skills, attitudes, and ethics in assessment. It is one of the important principles of improvement and student achievement measurement in nursing education.

One of the assessment method been employed by the Nurse educator to assess students clinical competences is Objective Structured Clinical Examination (OSCE). It is conducted by means of rotating students in successive stations that assess students' skills in history taking, physical examination, communication skills, patient management, diagnosis and data interpretation.

Objective Structured Clinical Examinations (OSCEs) are the most valid assessment measurement. These authors assert that more studies are needed that use the OSCE as an evaluation measure [7]. The OSCE is becoming more prevalent within healthcare education programmes, because it is regarded as a useful method for assessing, skills, and underpinning knowledge required for practice [2]. 
Perception of Final Year Nigeria Nursing Students on Objective Structured Clinical Examination: A viewpoint of Oyo State College of Nursing and Midwifery, Eleyele, Ibadan, Nigeria

\section{Methodology}

The study was carried out among the Basic Nursing student of the Oyo State College of Nursing and Midwifery, Eleyele, Ibadan. 100 students were selected as respondents from the two sets of 2015 and 2016. Questionnaires were administered on them to elicit their responses on OSCE examination.

\section{DATA ANALYSIS}

100 students were sampled and the results were subjected to analysis using SPSS 20.0 software

Table1. On Awareness on the use of OSCE for practical examination

\begin{tabular}{|l|l|l|l|}
\hline Variables & Frequency & Percent \\
\hline \multirow{4}{*}{ Do you know the aim, goals and procedure of OSCE } & Yes & 48 & 48.0 \\
\cline { 2 - 4 } & No & 42 & 42.0 \\
\cline { 2 - 4 } & Undecided & 10 & 10.0 \\
\cline { 2 - 4 } & Total & 100 & 100.0 \\
\hline \multirow{4}{*}{ Is Instruction for each station clear? } & Yes & 55 & 55.0 \\
\cline { 2 - 4 } & No & 37 & 37.0 \\
\cline { 2 - 4 } & Undecided & 8 & 8.0 \\
\cline { 2 - 4 } & Total & 100 & 100.0 \\
\hline \multirow{4}{*}{ Is the instrument for each station adequate } & Yes & 23 & 23.0 \\
\cline { 2 - 4 } & No & 72 & 72.0 \\
\cline { 2 - 4 } & Undecided & 5 & 5.0 \\
\cline { 2 - 4 } & Total & 100 & 100.0 \\
\hline OSCE Question station covered all types of questions? & Yes & 55 & 55.0 \\
\cline { 2 - 4 } & No & 31 & 31.0 \\
\cline { 2 - 4 } & Undecided & 14 & 14.0 \\
\cline { 2 - 3 } & Total & 100 & 100.0 \\
\hline
\end{tabular}

Table 2 revealed that $49.0 \%$ disagreed with the OSCE been a good way to assess the skills of nursing students, $48.0 \%$ disagreed with OSCE evaluation covering the entire range of practical skills, $45.0 \%$ agreed that OSCE test encompasses and basic statistical analyses such as frequency distributions and tables were used.

\section{RESULTS AND DISCUSSION OF FINDINGS}

Table 1 shows that majority (48.0\%) were aware about the aims, goals and procedure of OSCE, $55.0 \%$ said that the instruction of each station were clear, $72.0 \%$ said that the instrument for each station were not adequate while $55.0 \%$ said that question station covered all types of questions.

Table2. Perception of students on structure and format of OSCE

\begin{tabular}{|c|c|c|c|}
\hline \multicolumn{2}{|l|}{ Variables } & Frequency & Percent \\
\hline \multirow{4}{*}{$\begin{array}{l}\text { Is OSCE a good way to assess the skills of } \\
\text { Nursing student? }\end{array}$} & Agree & 40 & 40.0 \\
\hline & Disagree & 49 & 49.0 \\
\hline & Undecided & 11 & 11.0 \\
\hline & Total & 100 & 100.0 \\
\hline \multirow{4}{*}{$\begin{array}{l}\text { Is evaluation through the OSCE cover the entire } \\
\text { range of practical skills }\end{array}$} & agree & 44 & 44.0 \\
\hline & disagree & 48 & 48.0 \\
\hline & undecided & 8 & 8.0 \\
\hline & Total & 100 & 100.0 \\
\hline \multirow{4}{*}{$\begin{array}{l}\text { OSCE test encompasses well-structured and } \\
\text { sequenced questions and procedures }\end{array}$} & agree & 45 & 45.0 \\
\hline & disagree & 40 & 40.0 \\
\hline & undecided & 15 & 15.0 \\
\hline & Total & 100 & 100.0 \\
\hline \multirow[t]{4}{*}{ Does the time allotted for each test appropriate } & agree & 20 & 20.0 \\
\hline & disagree & 73 & 73.0 \\
\hline & undecided & 7 & 7.0 \\
\hline & Total & 100 & 100.0 \\
\hline \multirow[t]{4}{*}{ OSCE test is a well-organized examination } & agree & 46 & 46.0 \\
\hline & disagree & 41 & 41.0 \\
\hline & undecided & 13 & 13.0 \\
\hline & Total & 100 & 100.0 \\
\hline
\end{tabular}

a well-structured and sequenced questions and procedures, $73.0 \%$ disagreed with the time allocation for each test been appropriate while $46.0 \%$ agreed that OSCE test is a well-organized examination. 
Perception of Final Year Nigeria Nursing Students on Objective Structured Clinical Examination: A viewpoint of Oyo State College of Nursing and Midwifery, Eleyele, Ibadan, Nigeria

Table 3 shows that $53.0 \%$ disagreed with OSCE been stress free, $50.0 \%$ agreed that OSCE prevents students from being afraid as a result of less interference from tutors, $89.0 \%$ of the

Table3. Showing perception of students on conduct of OSCE

\begin{tabular}{|c|c|c|c|}
\hline \multicolumn{2}{|l|}{ Variables } & Frequency & Percent \\
\hline \multirow[t]{4}{*}{ OSCE set-up was stress free } & Agree & 39 & 39.0 \\
\hline & Disagree & 53 & 53.0 \\
\hline & Undecided & 8 & 8.0 \\
\hline & Total & 100 & 100.0 \\
\hline \multirow{4}{*}{$\begin{array}{l}\text { OSCE prevents students from being afraid as a } \\
\text { result of less interference from tutors }\end{array}$} & agree & 50 & 50.0 \\
\hline & disagree & 38 & 38.0 \\
\hline & undecided & 12 & 12.0 \\
\hline & Total & 100 & 100.0 \\
\hline \multirow{4}{*}{$\begin{array}{l}\text { OSCE follows a continuous movement from } \\
\text { station to station }\end{array}$} & agree & 89 & 89.0 \\
\hline & disagree & 10 & 10.0 \\
\hline & undecided & 1 & 1.0 \\
\hline & Total & 100 & 100.0 \\
\hline \multirow[t]{4}{*}{ Examiners presence at each station helps } & agree & 21 & 21.0 \\
\hline & disagree & 60 & 60.0 \\
\hline & undecided & 19 & 19.0 \\
\hline & Total & 100 & 100.0 \\
\hline
\end{tabular}

Table 4 shows that $84.0 \%$ agreed that OSCE lessen the interference from the examiners, $53.0 \%$ agreed that OSCE shows the student actual performance's, $51.0 \%$ disagreed with OSCE militating against influence of luck, $63.0 \%$ agreed that OSCE set-up allows confidence to respondents agreed that OSCE follows a continuous movement from station to station while $60.0 \%$ disagreed with examiners presence at each station been a help. build up, $56.0 \%$ agreed that scoring is objective and transparent, $72.0 \%$ disagreed that OSCE reduces failure, $70.0 \%$ disagreed that OSCE gives better opportunities than conventional clinical procedures while $53.0 \%$ agreed that the environment where OSCE is conducted is conducive for the procedure.

Table4. Showing perception of students on appraisal of OSCE

\begin{tabular}{|c|c|c|c|}
\hline \multicolumn{2}{|l|}{ Variables } & Frequency & Percent \\
\hline \multirow[t]{3}{*}{ OSCE lessens interference from the examiners } & Agree & 84 & 84.0 \\
\hline & Disagree & 16 & 16.0 \\
\hline & Total & 100 & 100.0 \\
\hline \multirow[t]{3}{*}{ OSCE shows the student actual performances } & agree & 53 & 53.0 \\
\hline & disagree & 47 & 47.0 \\
\hline & Total & 100 & 100.0 \\
\hline \multirow[t]{3}{*}{ OSCE militates against influence of luck } & agree & 49 & 49.0 \\
\hline & disagree & 51 & 51.0 \\
\hline & Total & 100 & 100.0 \\
\hline \multirow[t]{3}{*}{ OSCE set-up allows confidence to build up } & agree & 63 & 63.0 \\
\hline & disagree & 37 & 37.0 \\
\hline & Total & 100 & 100.0 \\
\hline \multirow[t]{3}{*}{ Scoring is objective and transparent } & agree & 56 & 56.0 \\
\hline & disagree & 44 & 44.0 \\
\hline & Total & 100 & 100.0 \\
\hline \multirow[t]{3}{*}{ OSCE reduces failure } & agree & 28 & 28.0 \\
\hline & disagree & 72 & 72.0 \\
\hline & Total & 100 & 100.0 \\
\hline \multirow{3}{*}{$\begin{array}{l}\text { OSCE gives better opportunities than the } \\
\text { conventional clinical procedures }\end{array}$} & agree & 30 & 30.0 \\
\hline & disagree & 70 & 70.0 \\
\hline & Total & 100 & 100.0 \\
\hline \multirow[t]{3}{*}{ The environment is conducive for the procedure } & agree & 53.0 & 53.0 \\
\hline & disagree & 47.0 & 47.0 \\
\hline & Total & 100 & 100.0 \\
\hline
\end{tabular}


Perception of Final Year Nigeria Nursing Students on Objective Structured Clinical Examination: A viewpoint of Oyo State College of Nursing and Midwifery, Eleyele, Ibadan, Nigeria

Table 5 shows that $68.0 \%$ agreed that time allocation for the test were insufficient, $65.0 \%$ disagreed with the limited number of stations been a problem, $57.0 \%$ agreed with the brevity of

Table5. Showing perception of students on problems and solution

\begin{tabular}{|c|c|c|c|}
\hline \multicolumn{2}{|c|}{ Variables } & Frequency & Percent \\
\hline \multirow{2}{*}{ Insufficient time allocation } & Agree & 68 & 68.0 \\
\cline { 2 - 4 } & Disagree & 21 & 21.0 \\
\cline { 2 - 4 } & Undecided & 11 & 11.0 \\
\cline { 2 - 4 } & Total & 100 & 100.0 \\
\hline \multirow{4}{*}{ Limited number of Stations } & agree & 26 & 26.0 \\
\cline { 2 - 4 } & disagree & 65 & 65.0 \\
\cline { 2 - 4 } & Undecided & 9 & 9.0 \\
\cline { 2 - 4 } & Total & 100 & 100.0 \\
\hline \multirow{3}{*}{ Brevity of instruction } & agree & 57 & 57.0 \\
\cline { 2 - 4 } & disagree & 24 & 19.0 \\
\cline { 2 - 4 } & Undecided & 19 & 100.0 \\
\cline { 2 - 4 } & Total & 100 & 65.0 \\
\hline \multirow{2}{*}{ The examiner not communicating during OSCE } & agree & 65 & 25.0 \\
\cline { 2 - 4 } & disagree & 25 & 10.0 \\
\cline { 2 - 4 } & Undecided & 10 & 100.0 \\
\cline { 2 - 4 } & Total & 100 & 67.0 \\
\hline \multirow{2}{*}{ Not having enough time to prepare } & agree & 67.0 & 27.0 \\
\cline { 2 - 4 } & disagree & 27.0 & 6.0 \\
\cline { 2 - 4 } & Undecided & 6.0 & 100.0 \\
\cline { 2 - 4 }
\end{tabular}

\section{Discussion}

From the study, $48.0 \%$ were aware about the aims, goals and procedure of OSCE, $55.0 \%$ said the instruction of each station were clear which is supported by the study of [8] that OSCE exam were identified by students, $58.6 \%$ stated that it covered a wide range of knowledge, $72.0 \%$ said that the instrument for each station were not adequate while $55.0 \%$ said that question station covered all types of questions.

The study further revealed that $49.0 \%$ disagreed with the OSCE been a good way to assess the skills of nursing students, $48.0 \%$ disagreed with OSCE evaluation covering the entire range of practical skills this disprove the study of [9]that $84.9 \%$ (57.6\% agreed, $27.3 \%$ strongly agreed) respondents felt that a wide range of clinical skills and competencies were covered, $45.0 \%$ agreed that OSCE test encompasses a wellstructured and sequenced questions and procedures this agreed with the study of [10] where $95.4 \%$ had the opinion that the examination was well organized and wellstructured and properly sequenced , $73.0 \%$ disagreed with the time allocation for each test been appropriate while $46.0 \%$ of the agreed that OSCE test is a well-organized examination. instruction, $65.0 \%$ agreed that the examiners not communicating during OSCE test were never a problem while $67.0 \%$ agreed that not having enough time to prepare for OSCE was a problem.
It was also revealed that $53.0 \%$ disagreed with OSCE been stress free, which agreed with the study of [11] which stated that $94 \%$ found the OSCE more stressful and mentally tougher than traditional exam formats despite the fact that they had been briefed and educated well regarding the nature and format of the exam they were going to take.50.0\% agreed that OSCE prevents students from being afraid as a result of less interference from tutors, $89.0 \%$ agreed that OSCE follows a continuous movement from station to station while $60.0 \%$ disagreed with examiners presence at each station been a help.

Furthermore, $84.0 \%$ agreed that OSCE lessen the interference from the examiners, $53.0 \%$ agreed that OSCE shows the student actual performance's, $51.0 \%$ disagreed with OSCE militating against influence of luck, $63.0 \%$ agreed that OSCE set-up allows confidence to build up, $56.0 \%$ agreed that scoring is objective and transparent, $72.0 \%$ disagreed that OSCE reduces failure, $70.0 \%$ disagreed that OSCE gives better opportunities than conventional clinical procedures while $53.0 \%$ of the respondents agreed that the environment where OSCE is conducted is conducive for the procedure.

Lastly, it was revealed that $68.0 \%$ agreed that time allocation for the test were insufficient, 
$65.0 \%$ disagreed with the limited number of stations been a problem, $57.0 \%$ agreed with the brevity of instruction, $65.0 \%$ agreed that the examiners not communicating during OSCE test were never a problem while $67.0 \%$ agreed that not having enough time to prepare for OSCE was a problem.

\section{CONCLUSION}

OSCE test is a relatively new test for testing the practical skills of students who are under training in nursing. The study showed that student's perception about it has been mixed. The study also revealed that time allocation for each question were insufficient, examiners need to look into this to arrive at a standardized time which will give the student enough time to exert their practical skills. Time that the student has for preparation needed to be looked into, all Colleges and School of Nursing needed to work their curriculum in a way that will give the student ample time to prepare themselves for the examination.

\section{REFERENCES}

[1] Hatamleh and Sabeeb. Journal of Healthcare Sciences ISSN 2348-5728 (Online). 2015 Vol. 2, Issue 2, pp: (52-56), Month: October 2014 March 2015.

[2] Merriman, C., and Westcott, L., Succeed in OSCEs and Practical Exams: An Essential Guide for Nurses, 1sted. Milton Keynes, Open University Press; 2010.

[3] Fidment, S. "The Objective Structured Clinical Exam (OSCE): A Qualitative Study exploring the Healthcare Student's Experience," Student Engagement and Experience Journal, 2012 vol. 1, no.1, pp. 1-11.
[4] Samira Alsenany and Amer Al Saif. Developing skills in managing Objective Structured Clinical Examinations (OSCE). Life Sci J. 2012; 9(3):597-602] (ISSN: 1097-8135).

[5] Rafiee G, Moattari M, Nikbakht A.N, Kojuri J, Mousavinasab M. Problems and Challenges of Nursing Students' Clinical Evaluation: A Qualitative Study. Iran J Nurs Midwifery Res. 2014; 19:41.[PMC free article] [PubMed] https://www.nursing.pitt.edu/admissions/clinica 1-experiences

[6] Cant R.P, Cooper S.J Simulation-based learning in nurse education: systematic review, $J A d v$ Nurs. 2010 66(1):3-15.

[7] Saadeldin A.I, Aamir A.H, Mohayad A.B Elhaj, K. E, Mohamed M. H, Mohammed E. A., Students' Perception of Surgical Objective Structured Clinical Examination (OSCE) at Final Year MBBS, University of Khartoum, Sudan. Medicine Journal. 2014 Vol. 1, No. 1, 2014 pp. 17-20.

[8] Riyadh M. A. A, Albert J. J. A. Scherpbier, H.A. A, Abdulhamza R.H, Maha A.M .A. Perception of OSCE Examination in Iraqi Undergraduate Medical Students. Karbala J. Med. 2015Vol.8, No.1, June.

[9] Lamia A. A, Sahar Ahmed, Alshamandy A.A and Nagat F. Abolwafa. Perception of Undergraduate Nursing Students towards Objective Structured Clinical Examination (OSCE). IOSR Journal of Nursing and Health Science (IOSR-JNHS) e-ISSN: 2320-1959.pISSN: 2320-1940 2017 Volume 6, Issue 5 Ver. VII. (Sep. -Oct .2017), PP 52-60

[10] Abidullah Khan et al. An Audit of the Medical Students' Perceptions regarding Objective Structured Clinical Examination; Education Research International Volume 2016, Article ID 4806398, 4 pages

Citation: Funmilayo Abiola Opadoja, Samuel Olukayode Awotona, Oluwaseun Lekan Ipadeola, Perception of Final Year Nigeria Nursing Students on Objective Structured Clinical Examination: A viewpoint of Oyo State College of Nursing and Midwifery, Eleyele, Ibadan, Nigeria. ARC Journal of Nursing and Healthcare. 2019; 5(2):27-32. doi: dx.doi.org/ 10.20431/2455-4324.0502004.

Copyright: () 2019 Authors. This is an open-access article distributed under the terms of the Creative Commons Attribution License, which permits unrestricted use, distribution, and reproduction in any medium, provided the original author and source are credited. 